\title{
Impact of Various Wrinkle Free Finishes on Wrinkle Recovery Property of Cotton Fabric under Different Variables
}

\author{
Tusief $\mathbf{M Q}^{1^{*}}$, Mahmood $\mathbf{N}^{1}$, Amin $\mathbf{N}^{2}$ and Saddique $\mathbf{M}^{1}$ \\ ${ }^{1}$ Department of Fibre and Textile Technology, University of Agriculture Faisalabad, Pakistan \\ ${ }^{2}$ School of Textile and Industrial Sciences, University of Management and Technology Lahore, Pakistan \\ *Corresponding author: Tusief MQ, Department of Fibre \& Textile Technology, University of Agriculture Faisalabad, Pakistan, Tel: 0300-7978955; E-mail: \\ qamartosief@yahoo.com
}

Rec date: Apr 29, 2014; Acc date: Jun 30, 2014; Pub date: Jul 12, 2014

Copyright: @ 2014 Tusief MQ, et al. This is an open-access article distributed under the terms of the Creative Commons Attribution License, which permits unrestricted use, distribution, and reproduction in any medium, provided the original author and source are credited.

\begin{abstract}
Today everybody wishes for that his/her dress retains just ironed shape. Wrinkle free finishes provide wrinkle free and soft look fabric. Wrinkle free finishes are broadly used in the textile industry to impart wrinkle-resistance to cellulosic materials such as cotton fabric. The application of wrinkle resistance (permanent or durable press) finishes on the fabric improves their wrinkle resistance property. Because of increasing demand for pure cotton fabrics, permanent press finishes are being used on these clothes. In conventional durable press finishing, there are two types of products used (resin type and reactant type). Both of these products contain formaldehyde which cause human carcinogen. Hence durable press finishes free of formaldehyde with trade namesTexicil DC, Knittex RCT, Arkofix NEC and Arkofix ELF (Dihydroxi ethylene urea and Demethyldihydroxi urea) were used in this research study. The present work endeavors to optimize the application of these wrinkle free finishes at various concentrations trying different techniques of applying these finishes on pure cotton fabric for best manufacturing results. The results revealed that the finish Arkofix ELF and Arkofix NEC showed superior results at the concentration level $120 \mathrm{~g} / \mathrm{l}$ under Pad-flash -cure method of application for the wrinkle free property of the fabric.
\end{abstract}

Keywords: Wrinkle free finishes; Wrinkle recovery; Fabric finishing techniques; Cotton; Woven fabric

\section{Introduction}

In textiles, when fabric is prepared, many processes are done to attain certain properties. One of them is wrinkle free. In the existing market, wrinkle-free action is functional to many types of garments, such as shirts, T-shirts and pants. In the last few years, cotton rich wrinkle-free shirts have taken off the market and the demand is increasing. This is in line with the change in life style, consumers require for value-added products, trend of back to natural and the increase in global journey. Thus garments with natural looking, comfort, attractive and wrinkle free are desirable [1].

One of the most important factors that affect the fabric quality is its ability to recover from wrinkle. Wrinkles are the fabric deformation that is based on its visco-elastic characteristics. Wrinkles are categories into two types, desirable wrinkle for good look of the fabric and undesirable wrinkles that occur during wearing. Most research studies focused on undesirable wrinkles. Fibers, yarn and fabric properties and finishing process play a great role in the development of wrinkles. Many factors like fiber type, bending performance of fibers, fiber diameter, twist in yarn, warp-weft density, fabric construction and fabric thickness, contribute in the development of wrinkles in the fabric. Some fibers like wool and silk have a good resistant to wrinkle while the cellulosic fibers like cotton, viscose and linen has very poor resistance to creasing [2]. Because of increasing demand for pure cotton fabrics, permanent press finishes are being used on these clothes. Normally cotton fibers are spun into yarn, woven into fabric then dyed and the last part of the process is treating it with a crosslinking agents. The applications of formaldehyde based reagents that are used to form these apparels are now creating ripples all across the globe backing up with concern for human health and environment. Earlier an organic acid called butanetetracarboxylic acid (BTCA) was used as an alternate formaldehyde. Due to the high cost of BTCA prevented its application on a commercial scale [3].

When fabrics are compressed during use and care like washing the wrinkles occur. The recovery of wrinkles depend on cross links which hold closest molecular chains together and pull them back into position after the fiber is bent, so it preventing the formation of a wrinkles. Durable press finishes are an important treatment for cotton fabrics which provide wrinkle resistant and permanent press performance for apparel. The cellulose chains are covalently bonded together by cross linking and these covalent bonds cannot be disrupted by water. In conventional durable press finishing, there are two types of products used (resin type and reactant type). Both of these products contain formaldehyde which cause human carcinogen. Some durable press finishes free of formaldehyde are dimethyl dihydroxy ethylene urea (DMDHEU), dihydroxy dimethyl imidazolidinone (DHDMI), polycarboxylic acids such as citric acid and butane tetracarboxylic acid, with hyposphosphite salts, imidazoles or sodium maleate, sodium tartrate or sodium citrate as catalysts, and citric acid as extender [4]. The finishing of cotton fabric for wrinkle resistance generally consists in the application of cross linking agents with suitable catalyst and softener, and in following application with the drying and heating to support cellulose cross linking reaction on the fabric. Concentration increasing of finishes shows some changing in results and the softening agent has an additional effect on fabric [5].

Since crease in cotton occurs due to the breakage of hydrogen bonds under stresses and the reshape of hydrogen bonds as cotton is 
not an elastic fiber. So there may be following ways to make cotton wrinkle free (prevent distortion of hydrogen bonds)

- Make cotton rigid : Which for obvious reason not recommended?)

- Make cotton elastic: Which for obvious reason not feasible

Therefore the only way left out will be to prevent distortion of hydrogen bonds which is being perfectly carried out by means of BLOCKING the hydrogen bonds forming groups by means of cross linking of -OH groups of cellulosic chains.

There are three most widely used techniques i.e. Pad dry method (Finish is applied and fabric is dried), Pad dry cure method (Here first fabric is dried and then cured after applying finish) and Pad flash cure method (here fabric, after finishing, is dried and cured in one operation in a stenter), to apply these finishes on the fabric. All these techniques have different effects on the fabric quality. Hence this study was conducted to evaluate the performance of the application of different wrinkle free finishes at various concentrations using different applying methods to optimize the quality of pure cotton fabric in respect of its wrinkle recovery property.

\section{Materials and Methods}

\section{Acknowledgment}

The research work entitled "Impact of Various Wrinkle free finishes on Wrinkle Recovery property of Cotton Fabric under different variables" was initiated in the Department of Fibre and Textile Technology, University of Agriculture Faisalabad and mainly conducted in the Sitara Textile Mills Ltd. Faisalabad, Pakistan.

\section{Methodology}

- The study was carried out step-wise as under

- Testing of grey fabric

- Singeing Desizing of fabric

- Fabric Scouring and Bleaching

- Dyeing of bleached fabric

- Finishing of fabric

- Analysis of fabric wrinkle recovery

\section{Testing of grey fabric}

The experimental material used for this research study was $100 \%$ cotton woven fabric in grey state.

\section{Fabric specification}

The fabric specifications are given as follows in Table 1:

\begin{tabular}{|l|l|}
\hline Weave & Plain (1/1) \\
\hline No. of Ends / inch & 60 \\
\hline No. of Picks / inch & 60 \\
\hline Warp Count (Ne) & $20 \mathrm{~s}$ \\
\hline Weft Count (Ne) & $20 \mathrm{~s}$ \\
\hline Wt. of Fabric & $125 \mathrm{~g} / \mathrm{m}^{2}$ \\
\hline
\end{tabular}

Table 1: Fabric Specifications

\section{Singeing conditions}

\begin{tabular}{|ll|}
\hline Flame Intensity & 17 \\
Temperature & $125^{\circ} \mathrm{C}$ \\
Speed & $80 \mathrm{~m} / \mathrm{min}$ \\
\hline
\end{tabular}

The fabric was passed rapidly over a row of gas flames at high speed $80 \mathrm{~m} / \mathrm{min}$ and then immediately into a quench bath to extinguish the sparks and cool the fabric.

\section{Desizing recipe}

\begin{tabular}{|ll|}
\hline TS-10 & $14 \mathrm{~g} / \mathrm{L}$ (desizer) \\
MRN & $10 \mathrm{~g} / \mathrm{L}$ (soap) \\
Wetting agent & $4 \mathrm{~g} / \mathrm{L}$ \\
$\mathrm{PH}$ & 7.5 \\
Temperature & $85^{\circ} \mathrm{C}$ \\
\hline
\end{tabular}

After Desizing the fabric was wrapped on a roller.

\section{Scouring recipe}

\begin{tabular}{|ll|}
\hline Caustic Soda & $30 \mathrm{~g} / \mathrm{L}$ (scouring agent) \\
K-D & $5 \mathrm{~g} / \mathrm{L}$ (soap) \\
Sacoron & $2 \mathrm{~g} / \mathrm{L}$ (Squinting agent) \\
Soda Ash & $4 \mathrm{~g} / \mathrm{L}$ \\
Temperature & $95^{\circ} \mathrm{C}$ \\
\hline
\end{tabular}

\section{Scouring procedure}

Cotton fabric was put into the scouring bath at about $50^{\circ} \mathrm{C}$ and then raising the temperature of bath up to $95^{\circ} \mathrm{C}$ and maintained the temperature for one hour. The bath was then allowed to cool at low temperature. The fabric was taken out, rinsed in hot and cold water respectively. Finally the sample was hydro extracted and dried.

\section{Bleaching recipe}

\begin{tabular}{|ll|}
\hline $\mathrm{H}_{2} \mathrm{O}_{2}(50 \%)$ & $32 \mathrm{~g} / \mathrm{L}$ (Bleaching agent) \\
$\mathrm{MLR}$ & $10: 1$ \\
$\mathrm{NaOH}$ & $(50 \%) 13 \mathrm{~g} / \mathrm{L}$ \\
$\mathrm{PN}$ & $3 \mathrm{~g} / \mathrm{L}$ (Wetting agent) \\
Sacoron & $2 \mathrm{~g} / \mathrm{L}$ (Squinting agent) \\
SIFA & $12 \mathrm{~g} / \mathrm{L}$ (Stabilizer) \\
Temperature & $95^{\circ} \mathrm{C}$ \\
Steaming Time & $40 \mathrm{~min}$. \\
\hline
\end{tabular}

\section{Bleaching procedure}

The scoured dry samples were put into the bleaching machine bath at about $40^{\circ} \mathrm{C}$ and then raised the temperature of the bath up to $95^{\circ} \mathrm{C}$. Maintaining this temperature for about one hour, the bath was 
Page 3 of 5

allowed to cool and at low temperature the samples were taken out, rinsed first in hot and then in cold water. Finally the samples were hydro extracted and dried [6].

\section{Dyeing of bleached fabric samples}

Dyeing is an important process in the wet processing of textile industry. After scouring and bleaching, the samples were subjected to dyeing with reactive dyes to evaluate the cotton fabric characteristics.

\section{Dyeing recipe}

\begin{tabular}{|ll}
\hline Dye 1.Drim Blue & $2.92 \mathrm{~g} / \mathrm{L}$ \\
Dye 2.Jack L Yellow & $1 \mathrm{~g} / \mathrm{L}$ \\
Anti-migrating agent (Soda Ash), $\mathrm{Na}_{2} \mathrm{Co}_{3}$ & $25 \mathrm{~g} / \mathrm{L}$ \\
Dye. leveling agent (Sodium Sulphate) & $20 \mathrm{~g} / \mathrm{L}$ \\
Urea & $100 \mathrm{~g} / \mathrm{L}$ \\
1st Washing & $\mathrm{Room}$ temperature \\
2ndWashing & $40^{\circ} \mathrm{C}$ \\
3rdWashing & $65^{\circ} \mathrm{C}$ \\
4thWashing & $\mathrm{Room}$ temperature
\end{tabular}

\section{Dyeing procedure}

Cotton samples were dyed with continuous method using reactive dye. The method consists of padding fabric at $30^{\circ} \mathrm{C}$ in a bath containing $100 \mathrm{~g} / \mathrm{l}$ urea, $2.92 \mathrm{~g} / \mathrm{l}$ Drim blue, $1 \mathrm{~g} / \mathrm{l}$ jack L yellow, $25 \mathrm{~g} / \mathrm{l}$ anti-migrating agent and $20 \mathrm{~g} / \mathrm{l}$ dye leveling agent. Urea besides helping in dissociation of the dye and swelling of cellulose, serves to hold moisture on fabric at high temperature to facilitate diffusion of dye. After padding the fabric was immediately dried without letting the dye to migrate. The dye was reacted with cellulose by heating for 60 seconds at $150^{\circ} \mathrm{C}$. A very thorough washing and soaping was done after dye fixation to remove the unfixed dye and to develop the true fastness of dyeing.

\section{Fabric finishing}

\begin{tabular}{|l|l|}
\hline Curing & Pad Dry \\
\hline
\end{tabular}

\section{Pick Up75\%}

The variables selected for finishing are given in Table 2.

\section{Test Method of the Study}

The Wrinkle Recovery of the fabric was tested according to AATCC [7] Test Method.

Principle: A test sample is wrinkled in standard atmospheric situation in a standard wrinkling device under a predetermined load for a prescribed period of time. The sampling is then reconditioned in the standard atmosphere for textile testing and evaluated for appearance by comparison with 3-dimensional reference standards.

Apparatus: Wrinkle Tester recommended by AATCC

- 3-Dimensional Wrinkle Recovery Replicas recommended by AATCC
- Standard conditions $\left(22 \pm 2^{\circ} \mathrm{C}\right.$ and $\left.65 \pm 2 \% \mathrm{RH}\right)$

- Fabric hangers with clips

- A lighting and evaluation area in a dark room using overhead lighting

Test Specimens: Three test specimens of $15 \times 28 \mathrm{~cm}$ each were taken and tested with the direction of the warp of woven fabric.

\begin{tabular}{|c|c|c|c|c|c|}
\hline \multirow[b]{2}{*}{ Finishes } & \multirow[b]{2}{*}{ Application Methods } & \multicolumn{4}{|c|}{ Concentrations } \\
\hline & & C1 & $\mathrm{C} 2$ & C3 & $\mathrm{C} 4$ \\
\hline \multirow[b]{3}{*}{ F1 } & T1 & 3 & 3 & 4-Mar & 4-Mar \\
\hline & $\mathrm{T} 2$ & 3 & 3 & 4-Mar & 4-Mar \\
\hline & T3 & 4-Mar & 4-Mar & 4-Mar & 4 \\
\hline \multirow[b]{3}{*}{$\mathrm{F} 2$} & T1 & 3 & 4-Mar & 4-Mar & 4-Mar \\
\hline & $\mathrm{T} 2$ & 4-Mar & 4-Mar & 4-Mar & 4 \\
\hline & T3 & 4-Mar & 4-Mar & 5-Apr & 5-Apr \\
\hline \multirow[b]{3}{*}{ F3 } & $\mathrm{T} 1$ & 3 & 4-Mar & 4-Mar & 4-Mar \\
\hline & $\mathrm{T} 2$ & 4-Mar & 4-Mar & 5-Apr & 5-Apr \\
\hline & T3 & 4-Mar & 4-Mar & 5-Apr & 5-Apr \\
\hline \multirow[b]{3}{*}{ F4 } & $\mathrm{T} 1$ & 4-Mar & 4-Mar & 4-Mar & 4 \\
\hline & $\mathrm{T} 2$ & 4-Mar & 4-Mar & 5-Apr & 5-Apr \\
\hline & T3 & 4-Mar & 4-Mar & 5-Apr & 5-Apr \\
\hline
\end{tabular}

Table 2: Variables selected for the study

Procedure: Raise top flange of wrinkle tester and hold in top position with locking pin. Wrap one long edge $28 \mathrm{~cm}$ of the specimen around the top flange of the AATCC Wrinkle Tester with the face side of the specimen on the outside and clamp it in position using the steel spring and clamp provided. Arrange the end of the specimen so that they are opposite to the opening in the spring clamp. Wrap the opposite long edge of the specimen around the bottom flange and clamp as describe above. Adjust the specimen by pulling on its bottom edge so that it lies smooth without sagging between the top and the bottom flanges. With draw the locking pin and lower the top flange gently with one hand until it comes to rest. Immediately place a total of 3500 grams weight on the top flange and record the exact time. After 20 min remove the weights, remove the springs and clamps, raise the top flange and gently remove the specimen from the tester so as not to distort any induced wrinkles. With a minimum of handling, place the shorter edge $15 \mathrm{~cm}$ under the clips on the cloths hanger and allow the specimen to hang vertically in the long direction. In the standard atmosphere after $24 \mathrm{~h}$ gently remove the hanger with the specimen to the evaluation site.

Evaluation: The standard having rating from 1-5 are used for the grading of fabric wrinkle recovery.

Atmospheric conditions: The testing of samples was carried out in laboratories where standard atmospheric conditions $65 \pm 5 \%$ relative humidity and $20 \pm 2{ }^{\circ} \mathrm{C}$ were maintained. 


\section{Results and Discussion}

\section{Fabric wrinkle recovery}

The visual results obtained by gray scale of fabric wrinkle recovery after applying wrinkle recovery finishes $(\mathrm{F})$ at different Chemical Concentration (C) and application methods $(\mathrm{T})$ is presented in Table-3. The results indicate that overall performance of F4 (4-5) is better than F1, F2 and F3 for fabric wrinkle recovery. For F1, F2 and F3 it ranges between good (3) to very good (3-4) while for F4 it ranges between very well to excellent. Wrinkle recovery increases with increasing chemical concentration. C3 and C4 showed better results than $\mathrm{C} 1$ and $\mathrm{C} 2$. These findings are in line with the results concluded in a previous study that dry wrinkle recovery angle (DWRA) and wet wrinkle recovery angle (WWRA) was increased with increasing agent concentration [8]. Similarly in another study it was disclosed the concentration of durable press finishing of cotton fabric provides a high-quality copolymer wrinkle resistance. Also wrinkle recovery angle (WRA) increased by increasing finishing agent concentration [8].

From the Table 3, it is clear that $\mathrm{T} 3$ showed better results than $\mathrm{T} 1$ and T2. The results get support from the research findings that the little wrinkle recovery in case of pad-dry technique is due to the retardation of the catalytic reaction of finishing agent which finally reduces the frequency of formation of cross-links within cellulose fiber structure. On the other hand, significant improvement of wrinkle recovery is observed both in case of pad-dry-cure and pad-flash-cure technique, but the pad-flash-cure technique showed the best result In case of chemical concentration $(C)$ the results showed that as we increase the chemical concentration the fabric wrinkle recovery increased [9].

\begin{tabular}{|c|c|c|c|c|c|}
\hline \multirow[b]{2}{*}{ Finishes } & \multirow[b]{2}{*}{ Application Methods } & \multicolumn{4}{|c|}{ Concentrations } \\
\hline & & C1 & $\mathrm{C} 2$ & C3 & $\mathrm{C} 4$ \\
\hline \multirow[b]{3}{*}{ F1 } & $\mathrm{T} 1$ & 3 & 3 & 4-Mar & 4-Mar \\
\hline & T2 & 3 & 3 & 4-Mar & 4-Mar \\
\hline & T3 & 4-Mar & 4-Mar & 4-Mar & 4 \\
\hline \multirow[b]{3}{*}{ F2 } & T1 & 3 & 4-Mar & 4-Mar & 4-Mar \\
\hline & T2 & 4-Mar & 4-Mar & 4-Mar & 4 \\
\hline & T3 & 4-Mar & 4-Mar & 5-Apr & 5-Apr \\
\hline \multirow[b]{3}{*}{ F3 } & $\mathrm{T} 1$ & 3 & 4-Mar & 4-Mar & 4-Mar \\
\hline & T2 & 4-Mar & 4-Mar & 5-Apr & 5-Apr \\
\hline & T3 & 4-Mar & 4-Mar & 5-Apr & 5-Apr \\
\hline \multirow[b]{3}{*}{ F4 } & $\mathrm{T} 1$ & 4-Mar & 4-Mar & 4-Mar & 4 \\
\hline & $\mathrm{T} 2$ & 4-Mar & 4-Mar & 5-Apr & 5-Apr \\
\hline & T3 & 4-Mar & 4-Mar & 5-Apr & 5-Apr \\
\hline
\end{tabular}

Table 3: Wrinkle recovery of fabric samples

$1=$ Poor; 2 = Moderate; 3 = Good; 4 = Very Good; 5 = Excellent

\section{Conclusions}

In this research various wrinkle free finishes (Texicil DC, Knittex RCT, Arkofix NEC and Arkofix ELF) applied to fabric at different concentrations $(60,80,100$ and $120 \mathrm{~g} / \mathrm{l})$ by adopting the different application methods (Pad-dry method, Pad-dry-cure method and Padflash-cure method). This study disclosed that the finish Arkofix ELF and Arkofix NEC showed superior results in respect of Fabric Wrinkle Recovery at concentration level $120 \mathrm{mg} / \mathrm{l}$, when applied by using Padflash-cure method. It is because pad-flash-cure technique for applying finish on cellulose fabric can form strong crosslink network with-in the microstructure of cellulose as compared to pad-dry and pad-drycure methods.

\section{References:}

1. Javed A (2010) To study the effect of various durable press finishes (resins) on cotton fabrics under different variables. Department of Fiber\& Textile Technology, University of Agriculture, Faisalabad, Pakistan 1-3.

2. Can Y, Akaydin M, Turhan Y, Ay E (2009) Effect of wrinkle resistance finish on cotton fabric properties. Indian J Fibre Text.34: 183-186.

3. Anonymous (2013) Wrinkle resistant cotton fabrics.

4. Sahin UK, Gursoy NC, Hauser P, Smith B (2009) Optimization of Ionic Crosslinking Process: An Alternative to Conventional Durable Press Finishing, Text Res J 79: 744-752.

5. Frick JG, Reeves WA, Pierce AG, Gaytreaux GA (2013) Wrinkle resistance finishes for cotton fabric using citric acid derivatives for soil release. U.S. Patent. 3,754,860.

6. Madaras GW, Parish GJ, Shore J (1993) Batchwise Dyeing of Woven Cellulosic Fabrics J Soc Dyers Colour 5: 3-24.

7. AATCC (2003) Measurement of fabric properties. AATCC Technical Manual Test method 135, 128. 
Citation: Tusief MQ, Mahmood N, Amin N, Saddique M (2014) Impact of Various Wrinkle Free Finishes on Wrinkle Recovery Property of Cotton Fabric under Different Variables. J Textile Sci Eng 4: 160. doi:10.4172/2165-8064.1000160

Page 5 of 5

8. Shyu JP, Chen CC (1992) Properties of Cotton Fabrics Crosslinked with Different Molecular Chain Lengths of Aldehyde Agents, Part I: Physical Properties and Agent Distribution. Text Res J 62: 469-474.
9. Datta C, Hansda M, Behera J, Haldar S (2013) Wrinkle recovery finishing for cellulosic fabric. 